\title{
LINGUAGENS NA TV
}

\author{
Glaucia Guimarães* \\ Raquel Goulart Barreto**
}

RESUMO: Este artigo aborda questões relativas às estratégias discursivas utilizadas na produção dos textos televisivos. Com base na Análise Crítica de Discurso (ACD), nos termos em que é formulada por Norman Fairclough, o trabalho analisa os modos pelos quais as linguagens (incluindo materiais semióticos diversos) são articuladas na/pela TV, sistematiza as relações entre a articulação de linguagens e a produção de efeitos de sentido, bem como os modos de sua inscrição nas tendências discursivas contemporâneas, a saber: democratização, tecnologização e comodificação. A partir das relações entre as práticas de linguagem e as tendências destacadas, o artigo tece considerações sobre as condições de produção de leituras críticas dos textos multimidiáticos, nas suas múltiplas dimensões: dos contextos e mecanismos da produção textual à pluralidade constitutiva de sua recepção.

Palavras-chave: Linguagens; Televisão; Efeitos de Sentido

\section{LANGUAGES ON TV}

ABSTRACT: This paper deals with issues related to discursive strategies in the production of TV texts. Based on Critical Discourse Analysis (CDA), as formulated by Norman Fairclough, it analyzes the ways languages (including several semiotic materials) are articulated in order to produce a range of wanted meaning effects, as well as the ways they are inscribed in the contemporary discursive trends discussed by the author, namely: democratization, technologization and commodification. Departing from the analysis of language practices and the discursive trends underlined, the paper aims at clarifying the multiple dimensions of multimedia conditions of production, focusing on both the context and the mechanisms and the diverse reception (reading) possibilities.

Keywords: Languages; Television; Meaning effects

\footnotetext{
* Professora na Faculdade de Formação de Professores (FFP) da Universidade do Estado do Rio de Janeiro (UERJ) e integrante do grupo de pesquisa Educação e Comunicação. E-mail: glauciaguimaraes@globo.com

* Professora do Programa de Pós-Graduação em Educação (ProPEd) da Universidade do Estado do Rio de Janeiro (UERJ), pesquisadora do CNPq, coordenadora do Grupo de Pesquisa Educação e Comunicação.E-mail: raquel@uol.com.br
} 
A leitura é uma questão crucial na escola, na medida em que não se restringe à aprendizagem da língua materna, interferindo positiva ou negativamente no trabalho com os mais diversos conteúdos. Longe de estarem resolvidas, as práticas de leitura têm de enfrentar o desafio de lidar com os textos que circulam socialmente, não mais restritos à linguagem verbal escrita (BARRETO, 2002). Partindo do pressuposto de que os novos textos implicam leituras qualitativamente diversas, o presente artigo visa a contribuir para ampliar as práticas de produção e de leitura de textos contemporâneos na escola, por meio da abordagem das estratégias discursivas utilizadas nos textos televisivos, identificando os efeitos de sentido, as estratégias discursivas de convencimento, de sedução e de formação do telespectador produzidos pelos modos de articulação de linguagens na/da TV.

O texto está organizado em quatro seções. A primeira caracteriza o contexto analítico e introduz aspectos conceituais da abordagem discursiva pretendida. A segunda apresenta uma análise dos modos como as linguagens são articuladas na TV, focalizando duas reportagens veiculadas no "Fantástico". A terceira sistematiza as relações entre a articulação de linguagens e a produção de efeitos de sentido, bem como os modos de sua inscrição nas tendências discursivas contemporâneas. Finalmente, a quarta seção tece considerações sobre as condições de produção de leituras críticas dos textos multimidiáticos, nas suas múltiplas dimensões: dos contextos e mecanismos da produção textual à pluralidade constitutiva da recepção.

\section{ASPECTOS CONCEITUAIS}

A televisão é um dos fenômenos sociais e culturais mais importantes da história da humanidade. Mesmo com o advento da Internet, nenhum outro meio de comunicação tem ocupado tantas horas da vida cotidiana dos cidadãos, com o mesmo poder de fascinação e de penetração. ${ }^{1}$ Nesse viés, Machado (1988, p. 8) afirma que a televisão entranhou-se tão profundamente na vida política das nações "que nada lhe pode ser 'exterior', pois tudo o que acontece de alguma forma pressupõe a sua mediação, acontece, portanto, para a tevê. Aquilo que não passa pela mídia eletrônica torna-se estranho ao conhecimento e à sensibilidade do homem contemporâneo". Esse é um dos motivos que levam Giroux (1995) a afirmar que ela representa uma das armas mais potentes da hegemonia. 
Partindo dessa premissa, este estudo objetiva compreender algumas das condições de produção do texto televisivo, identificando os efeitos de sentido, as estratégias discursivas de convencimento, de sedução, de formação do telespectador, produzidos pelos modos de articulação de linguagens. Por linguagens, compreende-se não apenas a formalização produzida na/pela Lingüística, mas pelas várias matérias (BARTHES, 1990) que produzem sentidos nas diversas práticas significantes socialmente desenvolvidas (KRISTEVA, 1988).

Procuramos compreender como as linguagens são articuladas na TV e como essa articulação funciona no processo discursivo, de modo a favorecer: (1) a leitura crítica dos modos de articulação de linguagens realizadas nas escolas e fora delas; e (2) a apropriação pedagógica dos textos contemporâneos, como meio de ultrapassar as leituras centradas na linguagem verbal escrita, na perspectiva do sentido único a ser "corretamente" interpretado (BARRETO, 2002).

Ao fazê-lo, não pretendemos simplesmente trilhar o caminho mais fácil de "desvelar" as intencionalidades das emissoras de TV, dos produtores e diretores de cinema, identificando ideologias, manipulações e distorções da "realidade" (FISCHER, 2006). Em primeiro lugar, porque "desvelar" remete à concepção de ideologia como mascaramento da realidade, indissociável do pressuposto de que seja possível "desideologizar", pela retirada de máscaras e véus, qualquer material semiótico. Em segundo, porque a perspectiva discursiva impede a identificação de uma agência, qualquer que seja ela, como origem dos sentidos. ${ }^{2}$ Em terceiro, porque, em se tratando dos percursos de sentidos, o foco na produção ou na recepção pode ser uma opção teórico-metodológica, sem implicar a exclusão das outras dimensões que constituem esses mesmos percursos: como são produzidos, como circulam, como são "lidos", como são legitimados, etc. Em outras palavras, "investigar as práticas discursivas como formas materiais de ideologia" (FAIRCLOUGH, p.116), pensando a última discursivamente como hegemonia de sentido, implica ter por horizonte as práticas significantes socialmente desenvolvidas, ainda que o recorte privilegie uma dimensão.

Este trabalho parte da ponta da produção das matérias televisivas, na perspectiva do discurso como modo de ação dialeticamente relacionado à estrutura social, destacando tendências que não remetem a determinações mecanicistas, mas a um conjunto de possibilidades de produção das suas leituras plurais, em práticas, idem. 
A análise apresentada a seguir é sustentada pela identificação dos modos pelos quais os sentidos são produzidos multimidiaticamente, em textualidade complexa, remetendo à reflexão sobre os gestos de leitura.

\section{A ARTICULAC̣ÃO DE LINGUAGENS NA TV}

As linguagens (palavra, imagem, som) não são apenas coexistentes (NUNES, 1998) ou complementares (BARTHES, 1990; SOUZA, 2001). Elas se articulam, remetendo a sentidos interessados e posicionados socialmente, produzidos a partir de dado contexto histórico, com vistas a determinados efeitos. ${ }^{3}$ Articuladas na TV, elas produzem efeitos de sentido (PÊCHEUX, 1992) complexos e difíceis de serem identificados, pois uma delas é capaz de enfraquecer ou reforçar a outra, o que pode dissimular, legitimar e nortear determinados sentidos, em detrimento de outros, também possíveis.

De acordo com Barreto (2002), há três modos básicos de articulação de linguagens: (1) a convergência, ou seja, o reforço mútuo de sentidos entre as matérias significantes; (2) a divergência, que consiste em articular matérias significantes, apontando para sentidos diferentes (por exemplo, com a imagem e a linguagem verbal parecendo não tratar do mesmo assunto); e (3) a contigüidade: proximidade muitas vezes associada à supressão de elementos que fariam parte de configurações textuais específicas.

No "Fantástico", programa de domingo da Rede Globo de Televisão, destacamos reportagens veiculadas no mesmo dia (18/03/2005), uma seguida da outra:

\section{Reportagem 1: Alunos humilhados, professores agredidos}

- Você viu no Fantástico no domingo passado: alunos são agredidos e humilhados por professores em salas de aula. Novas denúncias, surgidas esta semana, envolvem ameaças, abuso de autoridade e constrangimentos (Pedro Bial com fundo musical dramático).

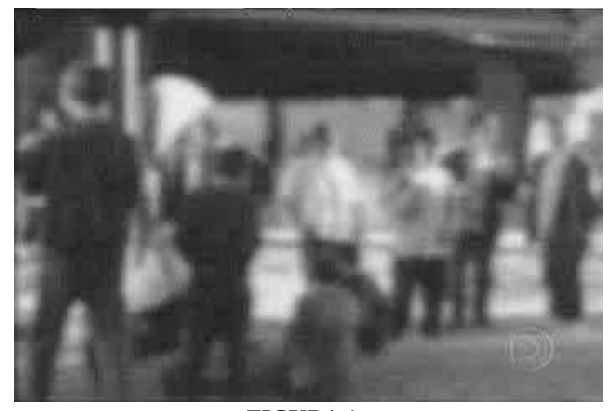

FIGURA 1 
- Hora do recreio. Hora da liberdade: lanche e brincadeiras. É o momento mais esperado pelas crianças, mas proibido até dois anos atrás para muitos alunos de uma escola pública de Mallet, a 220 quilômetros de Curitiba (Renata Ceribelli, em off, com fundo musical em tom grave e cenas desfocadas, em preto e branco, de alunos em pátio de escola).

A partir daí, mesclam-se vários depoimentos de alunos, professores e pais de alunos reclamando uns dos outros, "retratando o caos" no qual se encontra a escola. As imagens e as falas remetem geralmente a tristeza, desespero e angústia.

\section{Reportagem 2: Amigos da Escola}

Em seguida, o tema da reportagem é o Projeto "Amigos da Escola", da Fundação Roberto Marinho. As imagens são claras e luminosas, a música de fundo é suave e alegre, a locução passa a ter uma entonação mais terna, os movimentos de câmera são mais delicados, os ângulos passam a ser menos austeros e abruptos. Os sorrisos dos entrevistados são sempre focalizados, os ângulos procuram ressaltar a superioridade de pessoas "simples" e "solícitas" (dentistas voluntários) e, entre outros aspectos, a entonação do apresentador ressalta, em todos os momentos de sua fala, "atos heróicos de solidariedade" dessas pessoas.

Olá. Olha, tente pensar numa ilha onde toda a população, toda, tem dor de dente! É difícil de imaginar, mas na Ilha do Teixeira, no Paraná, a cárie era 0 maior problema de todos os moradores. Mas isto antes dos "Amigos da Escola" entrarem em ação. Agora... bem, agora todo mundo ri à-toa!" (Toni Ramos ${ }^{4}$, em sua fala, dá ênfase às palavras grifadas).

Nessa reportagem, as cenas, os sons, as imagens e as palavras são pautadas pela "solução" para "o maior problema de todos", trazida pelo projeto.
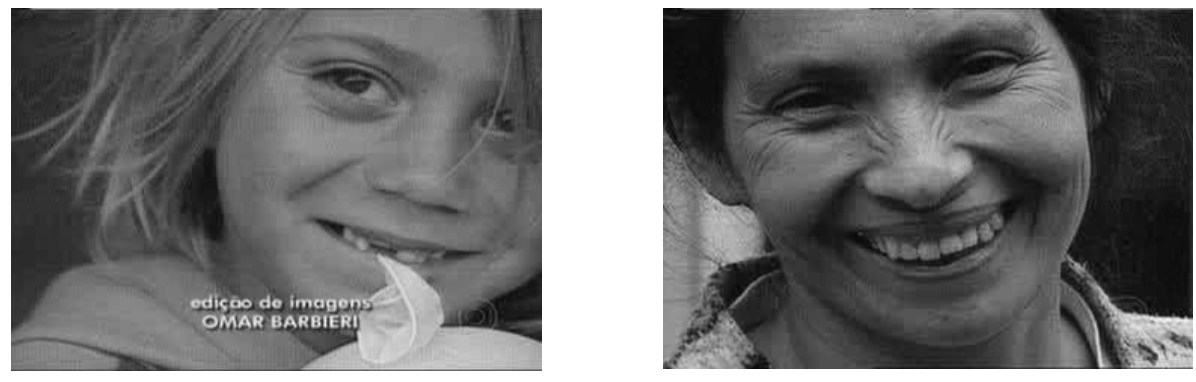

FIGURAS 2 e 3 
Essas duas reportagens articulam de modo convergente as linguagens que as compõem e a contigüidade entre elas sublinha o contraste entre a escola mostrada, da qual se afastou o poder público, e a "assistida" pelo modelo de voluntariado destacado. Embora a segunda reportagem não trate da função precípua da escola, sua proximidade temporal e temática remete à articulação por contigüidade. O contraste documentado favorece a fixação de sentidos, pela redução da polissemia à paráfrase (ORLANDI, 1987).

A Rede Globo explicitamente faz campanha em favor do projeto que financia. No entanto, quando essa campanha está dentro de um programa jornalístico e não nos comerciais do intervalo, a publicidade se "disfarça" em informação e, portanto, se configura como uma campanha publicitária velada. Em uma campanha publicitária, nos intervalos comerciais, é nítido o propósito de "vender" alguma idéia, mas em uma reportagem, o telespectador é "pego" desprevenido. Os textos publicitários stricto sensu não dissimulam o seu aspecto interessado/ interesseiro, o que concede à "reportagem" inúmeras prerrogativas em termos retóricos. Além disso, essa "campanha" é configurada a partir de diálogos (ou pseudo-diálogos), como textos interdiscursivos e imagens de diferentes pessoas, como se "comprovassem" ou "corroborassem" a tese presente nas duas reportagens. Outro aspecto se refere ao modo implícito pelo qual se defende o projeto, com a participação de "pessoas comuns" da ilha.

\section{OS EFEITOS DE SENTIDO E SUA INSCRIC̣ÃO NAS TENDÊNCIAS DISCURSIVAS CONTEMPORÂNEAS}

Esses modos de articulação de linguagens têm favorecido a produção de efeitos presentes nos mais diversos programas da televisão brasileira, identificados na tese que sustenta este trabalho (GUIMARÃES, 2006) como: (1) efeito de interlocução; (2) efeito de real; e (3) efeito de hiper-real.

O efeito de interlocução é produzido pela presença de pessoas "reais" (não são atores ou são atores desconhecidos representando pessoas comuns da sociedade), de modo a dissimular que o programa de TV apenas "capturou", e não "representou", a opinião de pessoas comuns ou o perfil do telespectador, tendendo a produzir a ilusão de que os telespectadores participam do que está sendo projetado. ${ }^{5}$

Em reportagens de menos de 3 minutos de duração, há mais de dez depoimentos ou imagens de pessoas comuns. Por exemplo, na 
reportagem sobre o Projeto "Amigos da Escola", de 2 minutos e 46 segundos de duração, cerca de 20 pessoas residentes em uma ilha no Paraná "exprimiram" sua opinião sobre o Projeto, confirmando a mudança supostamente produzida.

Para produzir esse efeito, grande quantidade de imagens e depoimentos de pessoas comuns de diversas regiões e lugares sociais está presente em interdiscursos aparentemente simétricos, sugerindo que as mais diferentes e desiguais vozes/imagens são contempladas e participam de forma equânime no discurso televisivo. Além disso, por meio da articulação das linguagens, é possível perceber a tentativa de aparentar que o espectador faz parte do espetáculo. São exemplos: programas de auditório e entrevistas de pessoas comuns em programas jornalísticos; apresentação de painéis com opiniões da audiência; "captação" das pessoas/personagens que participam dos reality shows; depoimentos de pessoas comuns, como na novela "Páginas da vida", endossando que a situação representada por atores foi vivenciada por elas; oferecimento de outros meios como Internet, telefone, correio para estabelecer a interlocução; links em sites para "mostrar" que o espectador pode interferir no conteúdo e na forma do programa (como ocorria no antigo programa "Você decide"; e ocorre nas eliminações dos participantes de reality shows, ou por meio do link "Você no Fantástico", que convida o telespectador a propor temas e reportagens para a produção do programa).

Outro aspecto interessante na produção desse efeito é o apelo a temas consensuais, geralmente de cunho educativo ou moralista, defendidos por variadas imagens e vozes. Esses temas, que geralmente eram mais tratados em documentários, em programas educativos ou jornalísticos, também passam a figurar nas novelas e de um modo especial. Para citar apenas alguns exemplos, pessoas que vivenciaram problemas na realidade estão presentes no enredo mesmo da novela e/ou em depoimentos ao final dos capítulos, em novelas como "O Clone", sugerindo como se livrar da dependência das drogas; na novela "Por amor", explicando a problemática que envolve o tratamento e a cura do câncer; na novela "América", endossando as questões sobre preconceitos vividos por cegos; e ainda na novela "Páginas da vida", reiterando apelos para que se incluam socialmente as pessoas com Síndrome de Down. Esse aspecto, além de poder produzir a ilusão de que a televisão é democrática, por "registrar" e difundir "opiniões diversas", pode causar a impressão de que a televisão "democratiza" conhecimentos "úteis" para a população e que é politicamente comprometida com a justiça social, podendo também 
produzir o que Sarlo (2000, p. 57) identifica como "efeito de informação".

O efeito de interlocução está inscrito na tendência discursiva que Fairclough (2001, p. 248) denomina "democratização": uma espécie de democratismo que inclui a aceitação de dialetos sociais e variações lingüísticas, a "eliminação de marcadores explícitos de poder em tipos de discurso institucionais com relações desiguais de poder, a tendência à informalidade das línguas, e mudanças nas práticas referentes ao gênero na linguagem", expondo, dessa maneira, pessoas comuns de vários segmentos sociais, fazendo com que não se perceba a impossibilidade de interlocução e de interatividade - limitação técnica própria da televisão, favorecendo a ilusão de que todos são iguais perante a TV.

O efeito de real, "de fazer ver e fazer crer no que faz ver" (BOURDIEU, 1997, p. 28), ${ }^{6}$ é produzido pelas imagens estáticas e em movimento, pelos sons e falas de pessoas e situações "reais", representadas de modo a caracterizar uma transmissão ao vivo e imparcial, e que, articuladas, enfraquecem, divergem ou se reforçam uma às outras, produzindo a impressão de transparência na representação do referente que, por conseguinte, pode possibilitar a confusão entre a representação e a realidade representada. ${ }^{7}$

Mesmo nos casos de transmissões gravadas em vídeo tape (VT), o discurso televisivo não apaga os sinais (imagéticos e sonoros) do "ao vivo"; pelo contrário, os reforça, possibilitando a impressão de que nada se interpõe entre a imagem/som e seu referente. O apelo discursivo não é apenas visual do tipo "veja para crer", mas, além do efeito probatório da imagem, o discurso televisivo tende a fazer "crer" no que "mostra", articulando linguagens, interpelando o telespectador com "dados do real". Como exemplo, podemos citar os shows gravados e editados para serem veiculados em VT, os programas jornalísticos que inserem alguns trechos que foram captados ao vivo e aqueles que nem sequer foram feitos ao vivo, como: "Programa Sílvio Santos", "Programa do Jô", "Pânico na TV”, que produzem as marcas de uma transmissão ao vivo, não só por ser esta a técnica original da TV, mas também para sustentar a credibilidade do meio (SARLO, 2000).

As reportagens desses programas também guardam algumas dessas marcas. Embora esteja claro que não se trata de uma transmissão ao vivo, alguns indícios não são apagados para reforçar a veracidade dos depoimentos. Esse reforço está: (1) no aproveitamento e na seleção de cenas nem sempre bem-enquadradas ou focadas pela câmera, com frases mal-construídas por aqueles que dão depoimentos, para parecer captação 
natural e não premeditada; (2) nas expressões, falas e entonações (imagens e sons) "naturais" das pessoas retratadas, que cada vez mais se tornam valiosas na televisão, em vários programas que "exibem" pessoas comuns em situações "reais", como o Big Brother Brasil; (3) na focalização exagerada das expressões e reações emocionadas, chegando a distorcer a imagem para sugerir pessoas reais, envolvidas em situações reais; (4) na exibição de significativo número de pessoas que dão depoimentos e, com eles, credibilidade aos casos focalizados.

No entanto, para dar ainda mais realismo às imagens e aos sons apresentados, há outro efeito do qual o discurso televisivo lança mão: o efeito de hiper-real. ${ }^{8}$ As linguagens procuram invariavelmente exacerbar o caráter emocional do que ou de quem está no foco das câmeras, por meio de enquadramentos, movimentos e efeitos especiais na imagem e no som, e ainda na produção de legendas que explicam o que é preciso ver ou ler, tornando o referente mais dramático e emocionante. Há algum tempo esse efeito somente era produzido em programas de ficção, mas hoje está presente em variados tipos de programas. No "Fantástico", por exemplo, as cenas tendem a incluir música de fundo e efeitos imagéticos cuidadosamente selecionados.

Para dar mais realismo, emoção e impressão de intimidade ou proximidade com as pessoas focalizadas, as imagens e sons do referente são representados e narrados como nas novelas e filmes de TV, reforçando as marcas emocionais do referente, por exemplo, (1) com os planos fechados nas expressões emocionadas; (2) com as curvas de entonação usadas pelos locutores; e (3) com o fundo musical acompanhando todas as falas e imagens das duas reportagens.

Por um lado, este tipo de efeito pode deixar clara a manipulação do verbal e do não- verbal, o que poderia anular o seu "efeito de real". Por outro, o efeito de hiper-real pode transformar uma situação corriqueira em espetáculo (DEBORD, 1997), fundindo "realidade" e "ficção", documentário e literatura, o concreto e o imaginado, tendendo a produzir também a confusão entre a realidade expressa e a realidade representada, como afirma Sfez (2000), ou ainda um real mais vívido e sedutor do que a dura realidade de fato, isto é, um "hiper-real", segundo a expressão de Baudrillard (1997) - coleção de cópias cujos originais foram perdidos, em que o referente vivido pelos homens desapareceu. Isso é sugerido, por exemplo, pela novela "Páginas da Vida", ao "retratar" de forma espetacular situações vividas por pessoas comuns, como Joana (criança portadora de Síndrome de Down que participa da novela), ou como as 
pessoas que davam seu depoimento ao final de cada capítulo para "comprovar" a existência das pessoas e das situações retratadas.

Atualmente, seja em programas jornalísticos, seja em novelas, as imagens, sons e palavras são apropriadas de situações reais (efeito de real) e de pessoas comuns (efeito de interlocução), mas a novela "Mulheres Apaixonadas", além de produzir uma ficção mais realista (efeito de hiperreal), pôde "produzir" realidade.

Inspirado no fato real de uma bala perdida que matou uma mulher no Rio de Janeiro, Manuel Carlos, autor da novela, "matou" uma das personagens e promoveu na novela uma passeata pelo desarmamento, levando para a ficção uma discussão que estava acontecendo na vida real. A passeata "da novela" de fato aconteceu, no dia 14 de setembro de 2003. Contou com a presença do ministro da Justiça, do presidente da Câmara dos Deputados e do secretário nacional de Segurança Pública, entre outros. Ao todo, 40 mil pessoas participaram do evento, debaixo de forte chuva. Dessas, apenas 200 eram figurantes e 43 atores/personagens da novela. Por meio desses efeitos, a representação produzida pela TV parece ser inspirada e também parece inspirar a realidade, ou (re)criá-la.

Pela articulação de linguagens e por seus efeitos de sentido, a produção televisiva está inscrita na tendência que Fairclough (2001) chama de "comodificação", compreendendo "a colonização de ordens de discurso institucionais e, mais largamente, da ordem de discurso societária por tipos de discurso associados à produção de mercadoria" (p. 255). E com a "aquiescência" dos mais diversos telespectadores (efeito de interlocução), tudo pode ser transformado discursivamente em mercadoria, em um "real espetacular" (efeitos de real e hiper-real), que apaga os limites entre o real e o ficcional, assim como entre as esferas pública e privada, gerando cada vez mais dividendos para as emissoras.

Em síntese, a televisão, articulando linguagens, oculta-se discursivamente como veículo ou como mediação na narração de fatos e, por meio das estratégias de produção de efeitos de sentido, sugere que seu texto não seja apenas democrático, mas transparente (espelho do "real").

\section{ARTICULAÇÃO DE LINGUAGENS E LEITURA DE TEXTOS CONTEMPORÂNEOS}

A construção do ideário de que a televisão se constitui como espaço democrático e transparente de reverberação do consenso popular pode fazê-la funcionar como lugar privilegiado de produção de "verdades" e de formação social e cultural dos sujeitos (FISCHER, 2005), 
(re)produzindo "ordens do discurso" (FOUCAULT, 2005), regras sociais, imaginários e tendências sociais mais amplas.

Sendo assim, embora saibamos que, por um lado, é impossível o controle das prováveis interpretações e usos dos textos televisivos, pois o espectador não é uma tabula rasa, por outro lado é necessário compreendermos as condições de produção dos discursos que, sob a forma de imensa quantidade de informação exposta diariamente - sobre a qual Courtine (2006, p. 26) questiona: “informação ou intoxicação?”-, tendem a favorecer a sua reprodução.

Nesse contexto, tentar dar conta das condições de produção que constituem os materiais de leitura que circulam socialmente é um movimento que parte do seguinte pressuposto: os novos textos implicam novos desafios para a leitura, dentro e fora da escola. Não é razoável supor que textos com texturas cada vez mais complexas possam ser pensados a partir dos mesmos gestos de leitura, por pelo menos duas razões. A primeira é o fato de que a leitura é a destinação de toda produção textual. A segunda razão diz respeito ao fato de que a negação das "teorias chamadas pesadas e monolíticas do poder" não pode significar "a celebração unívoca do retorno ao sujeito-receptor e de seu poder para determinar o sentido do que consome" (MATTELART, 2006, p. 242).

O foco no conhecimento de como se produzem os discursos pela articulação de linguagens pretende ser, ao mesmo tempo, convite e subsídio para ampliar a leitura crítica dos textos contemporâneos. Um convite ao trabalho com textos significativos, considerados no contexto dos seus processos discursivos, abrindo diferentes possibilidades de leitura. Por isso, buscar "dar conta das tramas que os constituem é um trabalho a ser produzido a partir da observação atenta da construção dos novos textos e da abertura para as várias leituras feitas pelos diferentes sujeitos, com suas histórias e seus lugares de ver/ouvir/dizer/ler"' (BARRETO, 2006, p. 2).

Em síntese, é importante que a escola se constitua como um espaço-tempo de comunicação, com base na exposição e na discussão dos diversos sentidos atribuídos aos textos contemporâneos, rompendo, a um só tempo, com o pressuposto do sentido único a ser "corretamente" interpretado na leitura dos textos e com a perspectiva da leitura reduzida à livre atribuição de sentidos pelo leitor. Se pretendermos que a educação se aproxime da área de comunicação, é preciso propiciar as condições para que, na escola, sejam formalizados conhecimentos sobre os textos que cir- 
culam na sociedade: dos contextos e mecanismos da produção textual à pluralidade constitutiva da recepção.

No contexto da sociedade midiatizada, os textos são multimidiáticos, tecidos pela articulação de linguagens e não pela simples coexistência de distintas ordens de materialidade em um mesmo espaço. Implicam, portanto, condições de realização de leituras que levem em conta a "dança das linguagens" no processo discursivo.

\section{REFERÊNCIAS}

ALVES, N. Tecer conhecimento em rede. In: ALVES, N.; GARCIA, R. L. (Org.). O sentido da escola. Rio de Janeiro: DP\&A, 2001.

BARRETO, R. G. Formação de Professores, tecnologias e linguagens: mapeando velhos e novos (des)encontros. São Paulo: Edições Loyola, 2002.

BARRETO, R. G. Mudaram os textos. E as leituras nas escolas? A página. Porto, ano 15, n. 155, abr. 2006. Disponível em: <http//www.apagina.pt/arquivo/ artigo.asp?ID $=4509>$. Acesso em: 20 abr. 2006.

BARRETO, R. G.; GUIMARÃES, G. C.; MAGALHÃES, L. K. C. de; LEHER, E. M. T. As tecnologias da informação e da comunicação na formação de professores. Revista Brasileira de Educasão. São Paulo, v. 11, n. 31, p. 31-42, 2006.

BARTHES, R. O óbvio e o obtuso: ensaios sobre fotografia, cinema, pintura, teatro e música. Rio de Janeiro: Nova Fronteira, 1990.

BAUDRILLARD, J. Tela total: mitos e ironias da era do virtual e da imagem. Porto Alegre: Sulina, 1997.

BOURDIEU, P. Sobre a televisão. Rio de Janeiro: Jorge Zahar, 1997.

COURTINE, J. J. O mentir verdadeiro. In: SWIFT, J. A arte da mentira politica. Campinas: Pontes, 2006.

DEBORD, G. A sociedade do espetáculo: comentários sobre a sociedade do espetáculo. São Paulo: Contraponto, 1997.

DUARTE, E. B. Televisão: ensaios metodológicos. Porto Alegre: Sulina, 2004.

FAIRCLOUGH, N. Discurso e mudança social. Brasília: UnB, 2001.

FISCHER, R. M. B. O estatuto pedagógico da mídia: questões de análise. Disponível em: $<$ http://www.educacaoonline.pro.br/o_estatuto_pedagogico.asp?f_id_artigo=173>. Acesso em: 15 dez. 2005.

FISCHER, R. M. B. Mídia, máquinas de imagens e práticas pedagógicas. Disponível em: $<$ http://www.anped.org.br/reunioes/29ra/trabalhos/trabalhos_encomendados/GT04 /2006\%20Trabalho\%20Encomendado\%20GT\%20Didática\%20ANPED.pdf >. Acesso em: 14 nov. 2006.

FOUCAULT, M. $A$ ordem do discurso. 12. ed. São Paulo: Edições Loyola, 2005.

GIROUX, H. Memória e pedagogia no maravilhoso mundo da Disney: In: SILVA, T. T. (Org.): Alienigenas na sala de aula: uma introdução aos estudos culturais em educação. Petrópolis: Vozes, 1995. p. 132-158.

GUIMARÃES, G. TV e escola: discursos em confronto. 4 ed. São Paulo: Cortez, 2003.

GUIMARÃES, G. $A$ articulação de linguagens na TV: questões educacionais para a sociedade multimidiática. Tese (Doutorado em Educação) - Faculdade de Educação, Universidade do Estado do Rio de Janeiro, Rio de Janeiro, 2006. 
KRISTEVA, J. História da linguagem. Lisboa: Edições 70, 1988.

MACHADO, A. A arte do vídeo. São Paulo: Brasiliense, 1988.

MARTÍN-BARBERO, J. Dos meios às mediações. Rio de Janeiro: Ed. UFRJ, 1997.

MATTELART, A. Para que "nova ordem mundial da informação"? In: MORAES, D.

(Org.). Sociedade midiatizada. Rio de Janeiro: Mauad, 2006. p.233-246.

NUNES, J. H. Aspectos da forma histórica do leitor brasileiro na atualidade. In: ORLANDI, E. P. (Org.). A leitura e os leitores. Campinas: Pontes, 1998. p. 25-46.

ORLANDI, E. P. A linguagem e seu funcionamento: as formas do discurso. Campinas: Pontes, 1987.

P CHEUX, M. Semântica e discurso: uma crítica à afirmação do óbvio. Campinas: Ed. da UNICAMP, 1992.

RAMONET, I. O poder midiático. In: MORAES, D. (Org.). Por uma outra comunicação: mídia, mundialização cultural e poder. São Paulo: Record, 2003. p. 243-252.

SARLO, B. Cenas da vida pós-moderna: intelectuais, arte e videocultura na Argentina. Rio de Janeiro: Ed. UFRJ, 2000.

SFEZ, L. Crítica da comunicação. 2 ed. São Paulo: Loyola, 2000.

SOUZA, T. C. A análise do não-verbal e os usos da imagem nos meios de comunicação. Ciberlegenda, n. 6, 2001. Disponível em: <http://www.uff.br/mestcii/tania3.htm>. Acesso em: 30 jun. 2006.

\section{NOTAS}

${ }^{1}$ A média semanal de audiência televisiva em diversos países é ainda muito alta. Segundo pesquisa da consultoria americana NOP World, divulgada pela BBC, em 27 de junho de 2005 , os brasileiros passam 18,4 horas semanais diante da telinha e ocupam o $8^{\circ}$ lugar em relação a outras nações. À frente do país, ficaram Tailândia (22,4 horas), Filipinas (21 horas), Egito (20,9 horas), Turquia (20,2 horas), Indonésia (19,7 horas), Estados Unidos (19 horas) e Taiwan (18,9 horas). É possível afirmar também que o hábito de assistir à televisão ocupa lugar privilegiado na escala de atividades dos brasileiros. $\mathrm{Na}$ mesma pesquisa, pode-se verificar a diferença das 18,4 horas semanais voltadas para a televisão, para as 17,2 horas sintonizados nas estações de rádio, para as 10,5 horas na Internet em atividades desvinculadas de assuntos de trabalho e 5,2 horas por semana para ler. Pesquisa recente registra "o significativo aumento do tempo gasto com o hábito de assistir à TV" e indica que, "no Brasil, adolescentes passam cerca de cinco horas por dia diante da TV" (<http://www.canalciencia.ibict.br/index.php>, fev. 2006). Além disso, a televisão é a tecnologia mais presente nos lares brasileiros, em todas as classes sociais (dados de pesquisa quantitativa realizada em agosto/setembro de 2005. Disponível em: $<$ http://www.nic.br/indicadores/usuarios/rel.geral-01.htm>).

${ }^{2}$ Como afirma Fairclough (2001), "a constituição discursiva de uma sociedade não emana de um livre jogo de idéias nas cabeças das pessoas, mas de uma prática social que está firmemente enraizada em estruturas sociais materiais, concretas, orientando-se para elas" (p. 92); e "os sujeitos são posicionados ideologicamente, mas também são capazes de agir criativamente no sentido de realizar suas próprias conexões entre as diversas práticas e ideologias a que são expostos e de reestruturar as práticas e as estruturas reposicionadoras" (p. 121).

${ }^{3}$ Ainda que não os garantam, vale insistir. 
${ }^{4}$ Cabe ressaltar que Toni Ramos é um ator da Rede Globo de Televisão que possui muita credibilidade junto ao grande público, o que reforça ainda mais a associação entre o projeto e solução para a escola.

${ }^{5}$ Vale ressaltar que Duarte (2004, p. 59) chama atenção para efeito televisivo semelhante, que denominou "efeito de interatividade", definindo-o como "estratégias que simulam uma relação direta com os espectadores através da conversão desses últimos em parte do espetáculo (programas de auditório), da incorporação de atores que atuam como delegados seus, da apresentação de painéis com opiniões da audiência, de recorrência a outros meios - telefone, internet, correio, etc.". O que chamamos de "efeito de interlocução" é diferente, na medida em que não se trata apenas de simular interatividade, mas de mostrar várias "pessoas comuns" como participantes da produção de sentidos na TV.

"Bourdieu (1997) associa a expressão "efeito de real" a uma das estratégias televisivas, considerando que é produzido pela força probatória da imagem, mas, em nossa perspectiva, o efeito é produzido pela articulação de linguagens, interpelando o telespectador também com os sons e as palavras "do real".

${ }^{7}$ Vale ressaltar que "os fatos não se narram a si mesmos, são narrados por um certo autor, de uma certa perspectiva, de uma certa maneira, para um certo público. Não são opiniões diferentes sobre os mesmos objetos: os autores se interessam por objetos diferentes". (ORLANDI, 1987, p. 77; grifos da autora)

8 Apesar do termo "hiper-real" ter sido cunhado por Baudrillard (1997), aqui é usado para definir efeito de sentido produzido especificamente pela televisão.

Recebido: 04/06/07

Aprovado: 13/09/07

Contato:

Rua Rui Barbosa, 280/204

Flamengo

Rio de Janeiro - RJ

BRASIL

CEP: 22250-020

E-mail: raquel@uol.com.br 